Вестник ПСТГУ.

Серия I: Богословие. Фрилософия.

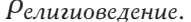

2017. Bun. 70. C. $47-62$

\author{
Гаспаров Игорь Гарибович \\ канд. филос. наук, \\ Воронежский государственный \\ медииинский ун-т им. Н. Н. Бурденко \\ 394036, Россия, г. Воронеж, ул. Студенческая, 10 \\ gasparov@mail.ru
}

\title{
ТожДЕСТво ЛИчНОсти
}

И ВОСКРЕШЕНИЕ МЕРТВЫХ

\author{
И. Г. ГАСПАРОВ
}

В статье рассматриваются аргументы известного американского аналитического философа религии, представителя «христианского материализма» Трентона Меррикса, которые он предлагает в защиту совместимости христианского учения о воскрешении мертвых с материалистическим пониманием природы человеческой личности. В статье «Воскрешение тела» Меррикс обсуждает два аспекта материалистической интерпретации учения о воскрешении тела. С одной стороны, он анализирует и пытается ответить на возражения против возможности всеобщего воскрешения тела в том случае, если материалистическое понимание природы человеческой личности было бы истинным, рассматривая прежде всего «проблему прерывающегося существования». С другой стороны, он приводит свои доводы, почему, с его точки зрения, материалистическое понимание лучше, чем его дуалистическая альтернатива, согласуется с учением о воскрешении мертвых. Автором дается критическая оценка аргументов Меррикса в поддержку материалистической интерпретации доктрины о воскрешении, а также показывается несостоятельность утверждения Меррикса о том, что учение о воскрешении не только совместимо с материалистическим пониманием человека, но и имеет смысл только в том случае, если мы полагаем себя тождественными со своим физическим телом. В заключение делается вывод, что апологетические аргументы Меррикса лишь частично достигают своей цели защитить учение о воскрешении мертвых от возражений, а само это учение представляется гораздо более осмысленным при принятии дуалистической интерпретации природы человека.

\section{Введение}

Не только христиане, но и представители других религий, например мусульмане или приверженцы некоторых направлений иудаизма, верят в воскрешение тела. В истории религиозной и философской мысли неоднократно предпринимались попытки рационально осмыслить содержание и последствия этой веры. Но каждая эпоха по-разному подходила к этой задаче, привнося собственный акцент и по-своему ставя проблему, корни которой уходят в глубокую древность. Наше время также не является исключением. Сегодня в аналитической теологии и философии религии ведутся оживленные дебаты на тему воскрешения мертвых. В современных спорах вопрос о воскрешении мертвых ставится в контексте идейного доминирования материализма, которое характерно для многих аналитических философов, занимающихся изучением проблем сознания и природы 
человеческой личности. Несмотря на приверженность материалистическому пониманию природы сознания и человеческой личности, некоторые из этих философов продолжают считать себя христианами, полагая, что их философские взгляды не только не противоречат, но и лучше сочетаются с христианской верой, данной Богом в Откровении. Можно даже утверждать, что сегодня в аналитической философии существует целая группа философов, которых можно назвать «христианскими материалистами». В отличие от своих единоверцев, занимающих дуалистические позиции, эти философы придерживаются мнения, что человек представляет собой полностью материальное существо, у которого нет души в смысле особой нематериальной, независимой в своем существовании от тела части. В качестве оправдания своей точки зрения они иногда даже ссылаются на философские взгляды некоторых отцов Церкви и древних церковных писателей, таких, например, как Тертуллиан ${ }^{1}$. Что касается вопроса о воскрешении мертвых, то позиция христианских материалистов сформировалась как ответ на возражение со стороны их атеистически или просто не-христиански настроенных коллег, согласно которому христианство вообще и учение о воскрешении тела в частности несовместимы с истиной материализма. По этой причине многие христианские материалисты обращаются к вопросу: совместимо ли учение о воскрешении мертвых с материализмом? И если да, то каким именно образом? Одной из первых публикаций на данную тему была знаменитая статья Питера ван Инвагена «Возможность воскресения» ${ }^{2}$. Эта работа вызвала дискуссию, в ходе которой возникло несколько моделей христианско-материалистического понимания воскрешения мертвых ${ }^{3}$. Именно в данном контексте следует рассматривать опубликованный в 2013 г. на русском языке перевод статьи известного

${ }^{1}$ В книге известного американского философа Хада Хадсона «Материалистическая метафизика человеческих личностей» можно найти своего рода манифест христианского материализма, а также попытку решить целый ряд теологических и моральных проблем, исходя из материалического толкования христианства (см.: Hudson H. A Materialist Metaphysics of Human Persons. Ithaka; L., 2000. P. 167-192).

${ }^{2}$ Van Inwagen P. The Possibility of Resurrection // International Journal for Philosophy of Religion. 1978. Vol. 9. 2. P. 114-121.

${ }^{3}$ В современной литературе выделяются четыре основные материалистские модели воскрешения мертвых: 1) симуляционная модель (П. ван Инваген), 2) модель «падающего лифта» (Д. Зиммермен), 3) конституционная модель (Л. Бекер), 4) антикритериалистская модель (Т. Меррикс). Согласно симуляционной модели Бог непосредственно после смерти прячет настоящее тело в удаленном уголке Вселенной, сохраняя его там нетленным, а на Земле заменяет его точной копией. В судный день настоящее тело воскрешается. Модель «падающего лифта» отличается от первой тем, что вместо простой замены настоящего тела копией Бог чудесным образом удваивает исходное живое тело, в результате чего на Земле остается «настоящий» труп, а живой организм отправляется в «иной мир», где он либо сразу оказывается в воскрешенном состоянии, либо ожидает воскрешения до дня всеобщего суда. Сторонники конституционной модели полагают, что для воскрешения человеческой личности Богу достаточно просто посредством Своей воли сообщить ей некую материю, которая будет ее конституировать после воскрешения. Антикритериалисты же утверждают, что не может быть никаких критериев тождества между умершим и воскресшим телом, как их нет и в обычной жизни, поскольку отношение тождества во времени следует считать базовым. Подробнее см.: Green J. Resurrection // Internet Encyclopedia of Philosophy. URL: http://www.iep.utm.edu./resurrec/ (дата обращения: 26. 11. 2016). 
американского философа Трентона Меррикса, посвященной проблеме воскрешения тела ${ }^{4}$. Меррикс является одним из апологетов материалистической трактовки этого учения. В своей статье Меррикс преследует двоякую цель. С одной стороны, он предлагает свои ответы на некоторые возражения против возможности телесного воскрешения в том случае, если человеческая личность является полностью материальной. С другой стороны, у Меррикса присутствуют и более амбициозные намерения. Он пытается показать, что сама вера в воскрешение мертвых имеет смысл только в том случае, если мы одновременно убеждены в том, что мы тождественны своему физическому телу. Такое истолкование данного положения христианской веры не может не вызывать множество теологических и философских вопросов. Ведь по существу оно бросает вызов традиционному пониманию христианского учения о воскрешении мертвых, который требует взвешенного и интеллектуально обоснованного ответа. Это обстоятельство и определило цель настоящей статьи - рассмотреть и дать критическую оценку как аргументам Меррикса в пользу совместимости учения о воскрешении тела с материализмом, так и и его версии материалистической интерпретации этого учения.

\section{Воскрешение тела \\ и проблема прерывающегося существования}

Меррикс следующим образом формулирует учение о воскрешении тела:

[B] вечности мы не будем чистыми духами или бестелесными душами. Напротив, у нас будут руки и ноги, форма и величина. Это так, потому что у нас будут тела. И не просто какие-нибудь тела. Каждый из нас обретет именно то тело, которым он или она обладали в этой жизни, хотя это тело и будет «прославленно». Каждый из нас сможет иметь то же самое тело потому, что в определенное будущее время все мертвые тела восстанут к новой жизни. То есть мертвые тела будут воскрешены. В самом деле, это мы сами будем воскрешены. В этом и заключается учение о воскрешении мертвых 5 .

Представляется, что такая формулировка предполагает истинность по крайней мере трех нижеследующих утверждений. Во-первых, что воскрешение моего тела произойдет в некий, более или менее отдаленный будущий момент времени. Во-вторых, мое воскресшее тело будет физическим, пусть и прославленным, телом. В-третьих, после воскрешения мое тело будет нумерически тождественно тому телу, которым я обладал в земной жизни. Таким образом, учение о воскрешении тела, как его формулирует Меррикс, сталкивается с очевидной проблемой: каким образом сохраняется нумерическое тождество моего тела в период времени между смертью и воскрешением, если этот период окажется достаточно долгим, ведь мое физическое тело имеет явную тенденцию к распаду вплоть до полного разложения? Если в какой-то момент - между моей смертью и воскрешением - мое физическое тело по какой-либо причине прекратит существова-

${ }^{4}$ Merricks T. The Resurrection of the Body // The Oxford Handbook of Philosophical Theology. Oxford, 2009. Р. 476-490 (Меррикс T. Воскрешение тела // Оксфордское руководство по философской теологии. М., 2013. С. 698-717).

${ }^{5}$ Меррикс. Указ. соч. С. 698. 
ние, то будет такой период времени, когда мое тело вообще не будет существовать. Поэтому из того, что утверждает Меррикс, следует, что воскрешение моего тела предполагает, что для него существует некая возможность преодолеть тот перерыв в существовании, когда оно не будет существовать вовсе ${ }^{6}$. Точнее, эту проблему можно сформулировать так: если всеобщее воскрешение мертвых возможно, то для некоторых тел должна быть возможность временного несуществования. Зачем нужна такая формулировка?

Рассмотрим представление о воскрешении мертвых, в соответствии с которым человеческое тело сначала умирает, затем в течение некоторого времени остается мертвым, а затем вновь обретает жизнь. Таким образом, одно и то же тело последовательно проходит три стадии: состояние жизни до смерти, мертвое состояние и состояние жизни после воскрешения. Следовательно, представление о воскрешении мертвых предполагает существование тела как минимум в три различных интервала времени: время, когда тело живо; время, когда то же самое тело мертво; время, когда то же тело вновь живо, но теперь оно уже не просто живо, но еще и «прославлено». Более того, это представление предполагает существование одного и того же тела во все эти три интервала времени. На первый взгляд все это верно в отношении Иисуса Христа, Который является моделью христианского воскресения par excellence. Тело Христа сначала было живо, затем пребывало мертвым во гробе и после этого обрело славу воскресения, но оно никогда не прерывало своего существования. Тело Христа восстало из гроба, но не прекращало существовать, пока пребывало в нем. Таким образом, можно сказать, что вышеописанное представление о воскрешении мертвых предполагает непрерывное существование человеческого тела в течение всего временного интервала между смертью и воскрешением. Поэтому можно было бы предположить, что либо история всех человеческих тел будет подобна истории тела Христа, либо что лишь тела тех из людей, которым повезет сохранить свое существование до дня воскресения, вновь обретут жизнь, познав вечное блаженство или вечную муку. Однако ни одно из этих предположений не представляется убедительным, так как, с одной стороны, согласно христианскому учению, все люди, а не только те, кому повезет, должны быть воскрешены в судный день (Ин 5. 28-29), а с другой стороны, по человеческому разумению невероятно, чтобы все человеческие тела просуществовали вплоть до судного дня. По этой причине временный перерыв в существовании представляет собой серьезное препятствие, для того чтобы мы могли бы помыслить себе воскрешение именно того тела, которым воскрешаемый человек обладал в своей земной жизни. Следовательно, можно было бы сформулировать следующее возражение против христианского учения о воскрешении мертвых:

(1) Воскрешение тел всех людей возможно, только если тела всех людей сохранятся до момента воскрешения.

(2) Тела некоторых людей полностью прекратят свое существование в момент времени еще до дня воскрешения.

(3) Следовательно, невозможно, чтобы были воскрешены тела всех людей.

${ }^{6}$ Меррикс. Указ. соч. С. 699. 
И. Г. Гаспаров. Тождество личности и воскрешение мертвых

Некоторые из современных метафизиков отрицают вторую посылку вышеприведенного аргумента. Питер ван Инваген предполагает возможность того, что Бог мог бы сохранять наши мертвые тела до Судного дня в нетронутом виде где-то в отдаленной части Вселенной, тогда как те тела, которые подвергаются тлению и в конечном итоге прекращают существование на земле, являются всего лишь их копиями ${ }^{7}$. В отличие от него, Меррикс признает истинность второй посылки, полагая, что, несмотря на то что некоторые человеческие тела прекратят свое существование еще до Судного дня, это тем не менее не станет препятствием для всеобщего воскрешения мертвых.

Меррикс сформулировал два, по его мнению, мнимых аргумента, каким образом временный перерыв в существовании мог бы разрушить христианское учение о воскрешении мертвых. Первый аргумент опирается на идею метафизического «основания», которая пользуется значительной популярностью в современной аналитической метафизике. В очень общем виде его можно было бы выразить следующим образом: если истинно, что $p$, то существует метафизическое основание, в силу которого истинно, что $p$. Применительно к учению о воскрешении мертвых это означает, что должно существовать какое-то метафизическое основание тождества тела, бывшего прежде живым, и тела, воскрешаемого в Судный день. Исходя из этого, Меррикс формулирует свой первый мнимый аргумент против возможности воскрешения тела следующим образом:

(1) Воскрешение тела возможно только в том случае, если существует метафизическое основание для тождества воскрешаемого тела на время прерывания его существования.

(2) Не существует никакого метафизического основания для тождества воскрешаемого на время прерывания его существования.

(3) Следовательно, воскрешение тела невозможно ${ }^{8}$.

Для того чтобы обосновать (2), Меррикс рассматривает трех возможных кандидатов на роль метафизического основания для тождества воскрешаемого тела: а) материальные части, некогда составлявшие жившее тело, которые могли бы быть вновь собраны в момент воскрешения; b) некая неуничтожимая материальная частичка прежнего тела, сохранение которой было бы гарантом его тождества с воскрешаемым телом; с) нематериальная душа, являющаяся метафизическим основанием тождества воскрешаемого тела на время прерывания его существования благодаря тому, что она остается той же самой в промежутке между смертью и воскрешением. Как полагает Меррикс, ни один из вышеперечисленных кандидатов не является удовлетворительным.

Что касается физических частиц, то они сами могут прекратить свое существование еще до нужного времени, как это, например, иногда происходит в случае ядерного взрыва, когда частицы переходят в энергию. Кроме того, физическая материя, входившая в определенное время в состав одного человека, в другое время может стать частью совсем другого человека или животного. Еще хуже то, что в разные моменты жизни одного человека его тело состоит из раз-

${ }^{7}$ Van Inwagen. Op. cit.

${ }^{8}$ Меррикс. Указ. соч. С. 700. 
ных материальных частиц, поэтому простое собирание материальных частиц, составлявших человеческое тело в определенный момент его жизни, само по себе не способно обеспечить его тождество в день воскресения. Что же касается некой неуничтожимой материальной частицы, которая могла бы быть носителем тождества всего тела, например некой косточки в основании позвоночника, о которой говорится в иудейской литературе ${ }^{9}$, то Меррикс полагает, что у нас едва ли есть основания верить в ее существование.

Также Меррикс приводит несколько аргументов, почему нематериальная душа не способна выполнять функцию надежного гаранта тождества тела, после того как тело, некогда связанное с этой душой, прекратило бы свое существование. Во-первых, неясно, как некий нематериальный объект, каковым является душа, вообще способен быть метафизическим основанием тождества некоего материального объекта, каковым является человеческое тело. Во-вторых, одна и та же душа может быть соединена с различными не-тождественными телами, так что если бы в день воскресения душа человека вошла в некое тело, то одно только тождество души еще не могло бы обеспечить надлежащее тождество тела. И, наконец, в-третьих, Меррикс утверждает, что учение о воскрешении тела само по себе дает «основание отрицать, что тождество тела в течение временного перерыва в его существовании может быть гарантировано сохранением тождества души» ${ }^{10}$.

Несмотря на это, Меррикс все-таки полагает, что у нас достаточно оснований, чтобы верить в возможность воскрешения тела, так как обе посылки вышеприведенного аргумента могут оказаться ложными. Во-первых, возможно, что у тождества тела вообще нет метафизического основания. Или же оно может иметь такое основание, которые мы не способны обнаружить ${ }^{11}$. Я полагаю, что эти доводы, предлагаемые Мерриксом, являются неудовлетворительными, поскольку маловероятно, чтобы тождество было лишено метафизического основания в том случае, если другие факты им обладают. Хотя в рамках настоящей статьи нет места, для того чтобы сколько-нибудь подробно рассматривать вопрос о существовании и сущности метафизических оснований, хотелось указать на то обстоятельство, что если бы такие основания существовали, то метафизика в целом была бы более разумным занятием, чем в случае, если бы таких оснований не было. И если все-таки предположить существование таких оснований, то представляется более вероятным полагать, что тождество тела ими обладает, поскольку тело вообще и человеческое тело в частности представляет собой скорее нечто сложное, чем простое, нечто скорее длящееся во времени, чем существующее мгновенно, нечто такое, что обладает тождеством благодаря чему-то иному, нежели благодаря самому себе. Что касается второго ответа Меррикса, согласно которому метафизическое основание тождества тела существует, но является непознаваемым, то я считаю его неудовлетворительным, поскольку оно по существу является просто отказом от метафизического рассмотрения вопроса,

${ }^{9}$ Shapiro $R$. The mystical bone of resurrection. 1987. URL:http://dx.doi.org/10.1148/ radiology.163.3.718 (дата обращения: 26. 11. 2016).

${ }^{10}$ Меррикс. Указ. соч. С. 703.

${ }^{11}$ Там же. 
так как если метафизическое основание существует, но не может быть познано с помощью того метода исследования, который предназначен для его познания, то это большая проблема для метафизического проекта как такового, и ставит под вопрос разумность всех метафизических аргументов, включая и те, которые предлагаются самим Мерриксом. Поэтому, я полагаю, ответы Меррикса скорее заводят в тупик метафизическое исследование проблемы воскрешения тела, нежели предоставляют нам рациональные доводы в защиту христианского учения о воскрешении мертвых ${ }^{12}$.

Второй аргумент против возможности воскрешения, который рассматривает Меррикс, утверждает, что воскрешение тела невозможно, поскольку оно предполагает как тождество между воскресшим и умершим телом, так и возможность прерывающегося существования этого тела. Однако два тела не могут быть тождественными, если они не существуют непрерывно в пространстве и времени. А потому очевидно, что оба этих условия не могут выполняться одновременно. Тем не менее Меррикс полагает, что это возражение представляет собой не более чем petitio principii ${ }^{13}$, так как это возражение предполагает как раз то, против чего оно направляется, а именно невозможность прерывного существования физического тела. В отличие от возражения Меррикса на первый аргумент, мы считаем, что в отношении второго аргумента он прав. Действительно, мы не можем верить, что нечто является невозможным, если заранее предполагаем невозможность этого. Однако именно это происходит в случае утверждения невозможности прерывающего существования для тела.

Для того чтобы оценить действительную силу второго возражения, которое Меррикс рассматривает в своей статье, необходимо рассмотреть принцип, лежащий в его основе. Согласно данному принципу, эксплицитно выдвинутому Дж. Локком ${ }^{14}$, невозможно, чтобы одна вещь имела два начала существования. Кажется, что Локк полагает, что данный принцип является универсально истинным. Тем не менее можно усомниться в этом, поставив вопрос, применим ли он к божественному всемогуществу, даже если его истина касается всех сотворенных вещей? Ведь поскольку воскрешение тела является божественным чудом, нельзя оставить без рассмотрения вопрос: может ли Бог сотворить одну и ту же вещь дважды? Некоторые средневековые авторы вполне допускали подобную возможность. Например, Фома Аквинский полагал, что хотя естественные силы не способны вернуть к существованию вещи, которые его утратили, Бог «способен восстановить эти вещи тождественными по числу, даже если они уже стали небытием», так как Он способен «производить последствия без опосредующих (intermediate) причин» ${ }^{15}$.

Кроме того, необходимо добавить, что прерывание существования представляется невозможным только с точки зрения одной из теорий пребывания

${ }^{12}$ Cp.: Drum P. On the resurrection of the body: discussion with Trenton Merricks // European Journal of Philosophy of Religion. 2011. Vol. 3. 2. P. 452.

${ }^{13}$ Меррикс. Указ. соч. С. 704.

${ }^{14}$ Locke J. An Essay Concerning Human Understanding II. XXVII. 1.

${ }^{15}$ Thomas Aquinas. Questiones de Quodlibet IV. 3. 2. Подробнее см.: Nevitt T. Survivalism, Corruptionism, and Intermittent Existence in Aquinas // History of Philosophy Quarterly. 2014. Vol. 31. 1. P. 1-19. 
во времени, эндурантизма ${ }^{16}$, сторонником которой является как сам Меррикс, так и, вероятно, большинство теологов и философов прошлого, писавших о воскрешении мертвых ${ }^{17}$. Однако в последнее время возникло несколько альтернативных объяснений того, как объекты продолжают свое существование во времени, с точки зрения которых прерывание существования объекта не представляет особенной проблемы. Наиболее известными из них являются пердурантизм $^{18}$ и эскдурантизм ${ }^{19}$. Согласно пердурантистскому представлению о том, как объекты продолжают свое существование во времени, объект существует во времени благодаря тому, что в каждый момент времени, когда он существует, у него есть временная часть. Если тело есть не более чем совокупность своих временных частей, то совершенно неочевидно, что оно не может иметь перерыва в существовании. Для эксдурантизма же прерывание существования не является чем-то необычным не только в случае воскрешения тела из мертвых. Ведь даже для продолжения существования в обычной повседневной жизни, как полагают сторонники этой позиции, мы продолжаем существовать только благодаря тому, что у нас есть двойник в каждый следующий момент нашего существования. Пердурантизм и эксдурантизм являются довольно экстравагантными теориями тождества объектов во времени, но едва ли их экстравагантность сама по себе может служить основанием, для того чтобы априори исключить их из рассмотрения, когда мы обсуждаем возможность воскрешения мертвых.

Таким образом, можно сделать вывод, что предлагаемая Мерриксом апология христианского учения о воскрешении мертвых лишь частично является удачной. Здесь можно согласиться с ним в том, что вероятность временного прерывания существования человеческого тела как таковая не отвергает возможности воскрешения этого тела. По этой причине возражение Меррикса на второй аргумент, как мне представляется, имеет важное значение для защиты христианского учения о воскрешении мертвых. В то же время его ответ на первый

16 Эндурантизм - философская теория пребывания объектов во времени, согласно которой объекты, будучи трехмерными, полностью пребывают в каждый момент своего существования. Таким образом, эндурантизм отрицает существование у объектов наряду с пространственными еще и временных частей. Многие, хотя и не все, современные христианские материалисты являются сторонниками эндурантизма. Наиболее яркие примеры - это П. ван Инваген, Т. Меррикс, М. Рей.

${ }^{17}$ Об общераспространенности эндурантистских убеждений среди философов и обычных людей до начала XX в. см.: Bigelow J. Presentism and Properties // Philosophical Perspectives / J. Tomberlin, ed. Oxford, 1996. Vol. 10. P. 35.

${ }^{18}$ Пердурантизм - философская теория пребывания объектов во времени, согласно которой объекты, будучи четырехмерными, пребывают во времени благодаря тому, что у них есть временная часть, т. е. максимальная совокупность их пространственных частей в определенный момент времени, в каждый момент времени, в которые они существуют. Пердурантизм является достаточно популярной теорией среди современных философов. Один из влиятельных сторонников пердурантизма - Дэвид Льюис. Среди христианских материалистов наиболее ярким примером сторонников пердурантизма является Хад Хадсон.

19 Эксдурантизм - философская теория пребывания объектов во времени, согласно которой существуют только мгновенные объекты, которые тем не менее могут обладать историческими свойствами благодаря тому, что у них есть двойники в предшествующие моменты времени. Наиболее известным сторонником эксдурантизма в современной метафизике является Тед Сайдер. 
И. Г. Гаспаров. Тождество личности и воскрешение мертвых

аргумент кажется мне слишком фидеистским, и я полагаю, что у нас имеется больше чисто философских ресурсов для защиты веры в воскрешение мертвых, чем утверждает Меррикс.

\section{Воскрешение и тождество личности}

В своей статье Меррикс не ограничивается негативной критикой невозможности материалистического понимания воскрешения мертвых, но и предлагает позитивную защиту этой позиции. Он пишет:

Наше тождество с телом превосходно объясняет, почему воскрешение наших тел будет нашим воскрешением. <...> Более того, иначе вообще трудно было бы объяснить, для чего нужно учение о том, что в день воскрешения человек вновь обретет свое тело, которое будет тождественно тому, что было у него в этой жизни. В самом деле, я вообще не могу себе представить какое-либо другое правдоподобное объяснение этому, тем более такое, которое могло бы соперничать с прямым и абсолютно убедительным объяснением, которое непосредственно вытекает из утверждения, что каждый из нас тождественен своему телу ${ }^{20}$.

И далее:

Я полагаю, что все это дает тем из нас, кто верует в воскрешение тела, равно как и тем, кто признает значимость этого учения, убедительное основание для заключения, что мы тождественны своему телу²1.

Таким образом, представляется, что Меррикс полагает, что учение о воскрешении тела как таковое влечет или предполагает определенное утверждение о тождестве личности, а именно утверждение, согласно которому мы тождественны своему телу. Однако возможно, что его точку зрения на отношение между учением о воскрешении тела и тезисом о тождестве личности было бы лучше охарактеризовать как некую разновидность объясняющего отношения, например как вывод к наилучшему объяснению, нежели импликацию или пресуппозицию. Так, согласно Мерриксу, если мы верим в свое тождество с телом, то совершенно ясно, почему мы в то же время склоняемся к тому, чтобы верить и надеяться на то, что в будущем мы воскреснем с теми же самыми по числу телами. Это потому, что в этом случае мы сами будем жить в будущем, т. е. воскрешение тела - это просто способ обрести жизнь после смерти. Таким образом, вера в воскрешение и вера в свое тождество с телом представляются убеждениями, которые взаимно поясняют друг друга.

Кроме этого, Меррикс также предлагает рациональный аргумент, почему мы должны верить в утверждение, что мы тождественны своим телам. Он называет его «трехшаговым аргументом», и его можно сформулировать следующим образом:

(1) Я в буквальном смысле обладаю некоторыми физическими свойствами, такими как величина, форма, положение в пространстве, масса и т. п.

${ }^{20}$ Меррикс. Указ. соч. С. 709.

${ }^{21}$ Там же. 
(2) Мои физические свойства не отличаются от физических свойств моего тела. Например, у меня такая же форма, как и у моего тела. Или я занимаю ту же область пространства, которую занимает мое тело, и т. п.

(3) Существует только один человекообразный объект с такими же физическими свойствами, которые есть у меня. То есть у него такая же форма, как у меня, такой же вес, как у меня. Он находится там же, где и я. И этот объект есть не что иное, как мое тело.

(4) Следовательно, я тождественен своему телу ${ }^{22}$.

Я полагаю, что этот аргумент был бы убедительным только в том случае, если предположить, что у нас есть только физические свойства. Однако вопреки данному предположению Меррикс эксплицитно признает, что помимо физических у нас есть также и ментальные свойства ${ }^{23}$. Если же мы признаем наличие у нас не только физических, но и ментальных свойств, то для того, чтобы сделать вывод о своем тождестве с телом, нам необходима еще одна дополнительная посылка в аргументе. Например, мы могли бы утверждать, что физическое тело, которое является носителем физических свойств, является также носителем ментальных свойств. Или же мы могли бы утверждать, что все мои ментальные свойства являются производными от физических свойств. Поэтому кажется, что мы должны принять следующую дизъюнкцию: либо у меня вообще отсутствуют ментальные свойства, либо все мои ментальные свойства являются производными от физических свойств, либо мое тело является носителем всех моих ментальных свойств.

Очевидно, что каждый член дизъюнкции является спорным. Однако в рамках настоящей статьи я предполагаю ограничиться рассмотрением последней части дизъюнкции, поскольку она представляется наиболее вероятным кандидатом на поддержку со стороны самого Меррикса, так как он эксплицитно отрицает первый член дизъюнкции и с высокой степенью вероятности стал бы отрицать второй ${ }^{24}$. С моей точки зрения, третий член дизъюнкции также является весьма проблематичным. Недавно Дин Зиммермен предложил убедительный аргумент в пользу того, что ни один обычный физический объект не способен быть носителем ментальных свойств в том случае, если последние имеют природу, отличную от природы физических свойств ${ }^{25}$. Согласно Зиммермену, основное препятствие заключается в неопределенности всех физических объектов повседневного опыта, таких, например, как мозг, нервная система или весь живой организм, которые могли бы быть наиболее подходящими кандидатами на роль материальных носителей ментальных свойств. Очевидно, что человеческое тело в этом отношении ничем не отличается от аналогичных физических объектов,

${ }^{22}$ Меррикс. Указ. соч. С. 13-14.

${ }^{23}$ Там же. С. 715 , примеч. 13.

${ }^{24} \mathrm{~K}$ такому выводу можно прийти на основании общей концепции природы человеческих личностей, которую Меррикс излагает в книге «Личности и объекты» и согласно которой человеческие личности, в отличие от неодушевленных объектов, обладают особыми ментальными силами (см.: Merricks T. Persons and Objects. Oxford, 2001. P. 85-117).

${ }^{25}$ Zimmerman D. W. From Property Dualism to Substance Dualism // Proceedings of the Aristotelian Society. 2010. Vol. 84. P. 119-150. 
из чего вытекает, что оно также неспособно быть адекватным носителем ментальных свойств. Следовательно, если у нас есть непроизводные от физических ментальные свойства, у которых предполагается наличие онтологически определенного носителя, то мы не можем быть тождественными своему телу, так как человеческие тела являются онтологически неопределенными объектами. Таким образом, один только факт, что мы в буквальном смысле обладаем физическими свойствами, не влечет за собой того следствия, что мы тождественны своему телу. Более того, как это признается самим Мерриксом, тот факт, что мы обладаем физическими свойствами непосредственно, является весьма спорным ${ }^{26}$.

Рассмотрим следующий вопрос: какие свойства представляются нам более тесно связанными именно с нами самими - физические, например такие, как положение в пространстве, форма или вес, или же ментальные, например такие, как мое видение цветов, слушание звуков, ощущение текстуры? Хотя на этот вопрос не так просто дать однозначный ответ, тем не менее после некоторого размышления многие люди говорят, что именно ментальные свойства являются нашими в буквальном смысле, тогда как физические свойства принадлежат нам лишь опосредованно, в силу того что они есть у нашего тела. Все эти размышления наводят на мысль, что предложенный Мерриксом трехшаговый аргумент в защиту нашего тождества с телом не является убедительным.

На это можно было бы возразить, что данный аргумент не нацелен на то, чтобы предоставить нам строгое и абсолютно убедительное доказательство нашего тождества с телом, а только лишь на то, чтобы пролить свет на тесную связь между нашим бытием вот этим телом и осмысленностью христианской надежды на воскрешение того же самого тела. Я полагаю, что в сущности Меррикс настаивает на том, что убеждение в нашем тождестве с телом и убеждение в его будущем воскрешении взаимно поддерживают друг друга. Отношение между этими двумя убеждениями можно было бы сформулировать следующим образом: вера в воскрешение тела становится понятной, если мы верим в свое тождество с телом. И наоборот, если мы верим в воскрешение тела, то делаем это именно потому, что верим в свое тождество с телом. Эти убеждения, по мнению Меррикса, взаимно оправдывают друг друга. С одной стороны, вера в воскрешение оправдывается верой в наше тождество с телом. С другой стороны, вера в воскрешение оправдывает наше убеждение в нашем тождестве с телом. Я не думаю, что есть что-то неверное в том, что некоторые убеждения могут взаимно оправдывать друг друга и проливать друг на друга свет, но в то же время считаю, что предположение нашего тождества с телом неспособно выполнять ту функцию, которую ему приписывает Меррикс.

Помимо своего трехшагового аргумента в качестве аргумента в пользу нашего тождества с телом, Меррикс приводит то, что без убеждения в своем тождестве с телом мы якобы не можем в буквальном смысле интерпретировать некоторые ключевые тексты Библии ${ }^{27}$. При этом он эксплицитно ссылается на Мф 27. 52-53:

${ }^{26}$ Например, см.: Lowe E. J. Subjects of Experience. Cambridge, 1996.

${ }^{27}$ Меррикс. Указ. соч. С. 709. 
...гробы отверзлись; и многие тела усопших святых воскресли и, выйдя из гробов по воскресении Его, вошли во святый град и явились многим.

Дан 12. 1-2:

И восстанет в то время Михаил, князь великий, стоящий за сынов народа твоего; и наступит время тяжкое, какого не бывало с тех пор, как существуют люди, до сего времени; но спасутся в это время из народа твоего все, которые найдены будут записанными в книге. И многие из спящих в прахе земли пробудятся, одни для жизни вечной, другие на вечное поругание и посрамление.

Ин 5. 28-29:

Не дивитесь сему; ибо наступает время, в которое все, находящиеся в гробах, услышат глас Сына Божия; и изыдут творившие добро в воскресение жизни, а делавшие зло - в воскресение осуждения.

\section{И 1 Фес 4. 16:}

...потому что Сам Господь при возвещении, при гласе Архангела и трубе Божией, сойдет с неба, и мертвые во Христе воскреснут...

Кроме этого, он ссылается также на Мф 14. 12-14, Деян 24, 1 Кор 15. Тем не менее, как кажется, мы не можем понять полный смысл этих текстов, если предположим, что мы тождественны своему телу и в последний день будем воскрешены в том же самом теле исключительно по этой причине.

Обратимся к одному из наиболее известных новозаветных текстов о воскрешении, 1 Кор 15. 35-55:

Но скажет кто-нибудь: как воскреснут мертвые? и в каком теле придут? Безрассудный! то, что ты сеешь, не оживет, если не умрет. И когда ты сеешь, то сеешь не тело будущее, а голое зерно, какое случится, пшеничное или другое какое; но Бог дает ему тело, как хочет, и каждому семени свое тело. Не всякая плоть такая же плоть; но иная плоть у человеков, иная плоть у скотов, иная у рыб, иная у птиц. Есть тела небесные и тела земные; но иная слава небесных, иная земных. Иная слава солнца, иная слава луны, иная звезд; и звезда от звезды разнится в славе. Так и при воскресении мертвых: сеется в тлении, восстает в нетлении; сеется в уничижении, восстает в славе; сеется в немощи, восстает в силе; сеется тело душевное, восстает тело духовное. Есть тело душевное, есть тело и духовное. Так и написано: первый человек Адам стал душею живущею; а последний Адам есть дух животворящий. Но не духовное прежде, а душевное, потом духовное. Первый человек - из земли, перстный; второй человек - Господь с неба... Каков перстный, таковы и перстные; и каков небесный, таковы и небесные. И как мы носили образ перстного, будем носить и образ небесного. Но то скажу вам, братия, что плоть и кровь не могут наследовать Царствия Божия, и тление не наследует нетления. Говорю вам тайну: не все мы умрем, но все изменимся вдруг, во мгновение ока, при последней трубе; ибо вострубит, и мертвые воскрес- 
нут нетленными, а мы изменимся. Ибо тленному сему надлежит облечься в нетление, и смертному сему облечься в бессмертие. Когда же тленное сие облечется в нетление и смертное сие облечется в бессмертие, тогда сбудется слово написанное: поглощена смерть победою. Смерть! где твое жало? ад! где твоя победа?

Здесь св. апостол Павел говорит не просто о воскрешении того же самого тела, но подчеркивает глубокое преображение прежнего человеческого тела, указывая на то, что в воскресении наше тленное тело станет «нетленным» (1 Kop 15. 52). Именно это преображение, а не просто восстановление тождества нашего земного тела является центральным фокусом учения св. апостола Павла о воскрешении. Он ясно выражает это, говоря, что «не все мы умрем, но все изменимся» (1 Кор 15. 51). В этом же направлении указывают и слова самого Иисуса Христа, произнесенные в знаменитом споре с противниками учения о воскрешении мертвых, саддукеями:

...ибо в воскресении ни женятся, ни выходят замуж, но пребывают, как Ангелы Божии на небесах (Мф 22. 30),

которые, согласно традиционной интерпретации, следует понимать так, что воскресшее человеческое тело, хотя и сохранит свою человеческую и «материальную» природу, тем не менее сама его «материальность» преобразится таким образом, что способ их существования станет весьма отличным от нынешнего ${ }^{28}$.

Более того, воскрешение тела всегда рассматривалось христианскими авторами в качестве необходимого элемента веры не потому, что они верили в то, что я тождественен с телом, но потому, что они считали, что мое тело является моей неотъемлемой частью. Даже такие раннехристианские авторы, как Тертуллиан, которого некоторые современные христианские философы причисляют к «христианским материалистам» ${ }^{29}$, утверждает со всей определенностью, что человеческое существо состоит из души и тела и что душа является его главенствующей и бессмертной частью ${ }^{30}$. Воскрешение же тела необходимо для восстановления целостности человеческого существа. Тертуллиан утверждает, что тело будет воскрешено, потому что оно было спутником души. Так было в прежней, временной жизни, так будет и в будущей, вечной жизни ${ }^{31}$ Таким образом, акцент здесь он делает не на нашем тождестве с телом, а на тесной связи между душой и телом, противопоставляя ее враждебности между ними. Вероятно, Тертуллиан тем самым хочет отвергнуть ту точку зрения, согласно которой тело как таковое является злом и потому не достойно войти в жизнь вечную. Действительно, в некоторых местах Тертуллиан говорит о «телесности» души ${ }^{32}$, что ясно указывает на его стоико-материалистические симпатии. Однако «материализм» Тертуллиана

${ }^{28}$ Подробнее см.: Ермилов П. В. Понятие «равноангельности» в святоотеческой традиции // Богословский сборник. М., 2005. Вып. 13. С. 55-100.

${ }^{29}$ Например: Hudson. Op. cit. C. 172.

${ }^{30}$ Tertullian. De resurrectione carnis 32; 35; 38. Также см.: Bonum $C$. $W$. The Resurrection of the Body in Western Christianity. N. Y., 1995. P. 36.

${ }^{31}$ Tertullian. De resurrectione carnis. 7.

${ }^{32}$ Ibid. 17. 
не похож на материализм современных «христианских философов», таких как Меррикс. Тертуллиан эксплицитно признает дуалистическую природу человека, составленного из теснейшим образом связанных между собой души и тела. Он утверждает, что, несмотря на то что душа является высшей частью человека, тело также должно быть воскрешено, поскольку оно соучаствовало в действиях души и потому должно разделить ее награду или наказание ${ }^{33}$. В этом отношении его позиция сохраняется в Церкви до наших дней.

Так или иначе, позиция Тертуллиана и церковная традиция наглядно показывают, что вопреки утверждению Меррикса учение о воскрешении тела является абсолютно осмысленным и без допущения нашего тождества с телом. Более того, кажется, что это его взгляд на связь между учением о воскрешении и тождестве личности не очень хорошо сочетается как со свидетельствами Священного Писания, так и с церковным Преданием. Проблемы, рассматриваемые Мерриксом, и предлагаемые им решения понятны скорее с точки зрения современной физикалистской концепции человеческой личности, нежели с точки зрения христианской веры. И хотя вполне можно допустить, что возможен пересмотр некоторых аспектов понимания веры в свете современного знания, этот пересмотр не может быть основан на манипулировании Священным Писанием или авторитетом древних авторов в пользу наших собственных предпочтений.

Ключевые слова: тождество личности, воскрешение мертвых, христианство, материализм, дуализм.

\section{Список литературы}

Ермилов П. В. Понятие «равноангельности» в святоотеческой традиции // Богословский сборник. М., 2005. Вып. 13. С. 55-100.

Меррикс T. Воскрешение тела // Окфордское руководство по философской теологии. М., 2013. C. 698-717.

Bigelow J. Presentism and Properties // Philosophical Perspectives / J. Tomberlin, ed. Oxford: Blackwell, 1996. Vol. 10. P. 35-52.

Bonum C. The Resurrection of the Body in Western Christianity. N. Y., 1995.

Drum P. On the resurrection of the body: discussion with Trenton Merricks // European Journal of Philosophy of Religion. 2011. Vol. 3. 2. P. 451-454.

Green J. Resurrection // Internet Encyclopedia of Philosophy. URL: http://www.iep.utm.edu./ resurrec/ (дата обращения: 26. 11. 2016).

Hudson H. A Materialist Metaphysics of Human Persons. Ithaka; L., 2000.

Lowe E. J. Subjects of Experience. Cambridge, 1996.

Merricks T. Persons and Objects. Oxford, 2001.

Merricks T. The Resurrection of the Body // The Oxford Handbook of Philosophical Theology. Oxford, 2009. P. 476-490.

Nevitt T. Survivalism, Corruptionism, and Intermittent Existence in Aquinas // History of Philosophy Quarterly. 2014. Vol. 31. 1. P. 1-19.

Shapiro R. The mystical bone of resurrection. 1987. URL: http://dx.doi.org/10.1148/ radiology.163.3.718 (дата обращения: 26. 11. 2016).

\footnotetext{
${ }^{33}$ Tertullian. De resurrectione carnis. 7.
} 
Van Inwagen P. The Possibility of Resurrection // International Journal for Philosophy of Religion. 1978. Vol. 9. 2. P. 114-121.

Zimmerman D. From Property Dualism to Substance Dualism // Proceedings of the Aristotelian Society, Supplementary. 2010. Vol. 84. P. 119-150.

\section{Personal IDENTITy AND RESURRECTION FROM THE DEAD}

\section{GASPAROV}

The paper examines arguments of the "Christian materialist" Trenton Merricks that he provided in support of the claim that the Christian doctrine of resurrection from the dead is compatible with the materialist understanding of the nature of human beings. In his paper The Resurrection of the Body, Merricks discussed two aspects of the materialist interpretation of the traditional religious doctrine of the bodily resurrection. On the one hand, he analyses and tries to overcome objections against the possibility of the general resurrection in case the materialist understanding of the nature of human personality should be true (mainly the problem of the temporal gap). On the other hand, he provides some reasons why the materialist understanding of human nature is more relevant than its dualist counterpart to the doctrine of the bodily resurrection. The present paper evaluates his arguments and discusses the suggestion that the doctrine of resurrection is not only compatible with materialism, but is also tenable if human beings are identical with their physical bodies. The conclusion of the paper is that Merricks' apologetic arguments achieve their aims in defending the doctrine of resurrection only partially; the resurrection doctrine appears more tenable if we accept the dualistic conception of human nature.

Keywords: Personal Identity, Resurrection, Christianity, materialism, dualism.

\section{References}

Ermilov P., "Ponjatie 'ravnoangel'nosti' v svjatootecheskoj tradicii”, in: Bogoslovskij sbornik, 2005, 13, 55-100.

Bigelow J., "Presentism and Properties", in: Philosophical Perspectives, 1996, 10 (Metaphysics), 35-52.

Bonum C., The Resurrection of the Body in Western Christianity, New York, 1995.

Drum P., "On the resurrection of the body: discussion with Trenton Merricks", in:
European Journal of Philosophy of Religion, 2011, 3, 2, 451-454.

Green J., Resurrection. Internet Encyclopedia of Philosophy, available at: http://www.iep. utm.edu./resurrect/ (26.11.2016).

Hudson H., A Materialist Metaphysics of $\mathrm{Hu}$ man Persons, Ithaka; London, 2000.

Lowe E. J., Subjects of Experience, Cambridge, 1996.

Merricks T., Persons and Objects, Oxford, 2001. 
Merricks T., "The Resurrection of the Body", Van Inwagen P., "The Possibility of Resurrecin: The Oxford Handbook of Philosophical Theology, Oxford, 2009, 476-490. tion", in: International Journal for Philosophy of Religion, 1978, 9 (2), 114-121.

Nevitt T., "Survivalism, Corruptionism, and Intermittent Existence in Aquinas" in: History of Philosophy Quarterly, 2014, 31 (1), 1-19.

Shapiro R., The mystical bone of resurrection, available at: http://dx.doi.org/10.1148/ radiology.163.3.718. (26.11.2016) Zimmerman D., "From Property Dualism to Substance Dualism", in: Proceedings of the Aristotelian Society, Supplementary, 2010, 84, 119-150. 